\title{
Los cuerpos y las mujeres kaqchikeles*
}

\author{
Emma Delfina Chirix García
}

A pesar del pensamiento biomédico occidental impuesto en la cultura maya, las mujeres kaqchikeles han sabido conservar un pie en la modernidad y otro en sus raíces histórico-culturales para mantener y legitimar creencias y prácticas culturales que les permiten reproducir el principio de cuidado de los cuerpos. Es importante recordar que la construcción del sentido de los cuerpos y de lo sexual no es el mismo en las diversas culturas.

\section{CUERPOY LENGUAJE}

A través del lenguaje y en su idioma, las mujeres kaqchikeles ${ }^{1}$ dan cuenta de las percepciones, experiencias y sentimientos que se articulan en torno a la construcción

${ }^{1}$ Es importante emprender un análisis que vaya más allá de la visión de género para mostrar otras identidades y realidades presentes no sólo en Comalapa (municipio donde se realizó la investigación), sino en la sociedad guatemalteca en general. de la sexualidad heterosexual. El vehículo que les permitió hablar abiertamente fue la confianza. A partir de este elemento se logró el diálogo y se establecieron buenas relaciones personales.

El lenguaje coloquial plasmado en el texto, conformado por palabras femeninas, es vertido en forma de historias, y da cuenta de particulares formas de expresión a través de metáforas y bromas por medio de las cuales se logra transmitir la experiencia de sentimientos como el amor, el dolor, el sufrimiento o el deseo.

Este lenguaje transmite una diversidad de ideas y de distintos modos de ver la vida y de expresar la sexualidad. La lengua kaqchikel impone otras categorías y, la mayoría de las veces, otro modo de ver el mundo. Implica también un modelo de apropiación por medio de las palabras que denota una concepción de la sexualidad y de la corporeidad humana ligada a la naturaleza y a la cultura. El lenguaje hablado por la comunidad kaqchikel prioriza la colectividad. Asimismo, comunica los saberes sólo si están asociados a la posibilidad de la experiencia. Por ejemplo, los niños y jóvenes adolescentes no deben saber de sexo, porque si lle-

\section{Bodies and Kaqchikele Women}

Emma Delfina ChIRIX GarCía: Doctorado en ciencias sociales, Centro de Investigaciones y Estudios Superiores en Antropología Social-Occidente, Guadalajara, México. emmachirix@gmail.com

Desacatos, núm. 30, mayo-agosto 2009, pp. 149-160

\footnotetext{
* Este artículo corresponde a uno de los capítulos de la investigación Una aproximación sociológica a la sexualidad kaqchikel de hoy, estudio que fue resultado de la maestría en ciencias sociales, cursada en la Facultad Latinoamericana de Ciencias Sociales (Flacso), Guatemala.
} 
gan a saber sobre este tema seguramente lo practicarán. Por esta misma razón se teme que, al hablar de sexualidad con los jóvenes, éstos vayan a disponer de una información que necesite ponerse a prueba. Por otra parte, en la actualidad las y los comalapenses ${ }^{2}$ acostumbran expresar sus ideas en dos idiomas: kaqchikel y castellano. En ambas lenguas son patentes las redes de poder que se plasman en palabras y que corresponden a la ideología dominante, con lo cual se mantienen los discursos, los estereotipos y la normalización de la sexualidad heterosexual. Esta última es identificada como un sistema político que puede ser cuestionado para descolonizar los cuerpos y la sexualidad de las mujeres indígenas y, además, porque el sistema de dominación patriarcal se sostiene precisamente en la sujeción de las mujeres a través de la heterosexualidad obligada.

Para transmitir su idea de la corporeidad humana, la lengua kaqchikel cuenta con signos, símbolos y sentimientos específicos, pero ante todo concibe al cuerpo como un todo, cuyas partes están interconectadas. Una de las formas para comprender al ser humano es mediante una trilogía que interrelaciona cuerpo, mente y espíritu. Estos tres elementos forman una unicidad y si se fragmentan provocan un desequilibrio en la vida de la persona. Esta cosmovisión indígena percibe al cuerpo como un ser viviente, con energías y sentimientos, y con necesidades, básicamente las relacionadas con la nutrición y la salud física y mental, y muy poco se habla sobre los deseos del cuerpo. Para algunas mujeres mayas profesionales el significado del cuerpo está vinculado con la autoestima, porque para ellas cuidar su cuerpo "es una forma de recuperar la autoestima, porque sienten la necesidad de quererse y de cuidarse", que también consiste en "dejar el dolor y el sufrimiento y aprenden a amarse" (Chirix García, 2003: 184).

Al retomar el cuerpo y el lenguaje en Comalapa, encontré que aún existe una abundante terminología para denominar al cuerpo y la sexualidad. Cuando se dice jari ruch'akul, significa "su cuerpo", y jari rutiyojil se refiere a

\footnotetext{
${ }^{2}$ San Juan Comalapa es un pueblo kaqchikel ubicado en el municipio de Chimaltenango, departamento que se encuentra en el centro de Guatemala.
}

"la gordura". En la identificación de las partes íntimas del cuerpo se emplean términos indirectos relacionados con la naturaleza: al órgano genital masculino (pene) se le identifica como tzik' in (pájaro) o rab'ajachin (órgano del hombre). Al órgano genital femenino (vulva) se le llama de varias maneras: rab'aj ixoq, meske'l (gato) o ru tutz'. Existen también expresiones duales sobre algunas partes del cuerpo; por ejemplo, en broma o metafóricamente, la vagina se relaciona con la boca; es posible decir ri jun ixok' k'o ka'i' ruchi', que significa "la mujer tiene dos bocas".

Uno de los centros importantes del cuerpo humano que se privilegia es el corazón: representa a la persona y se le nombra ranima. Al corazón se le identifica como sede principal de la razón y los sentimientos, por lo que es común escuchar frases como kan k'i nuna'ri wanima (está contento mi corazón), chke' nubij awanima (qué dice tu corazón) o noqa' pa awanma chkexin bij apochawe (recordá en tu corazón lo que te dije esa vez). El dolor de corazón no se localiza físicamente en el lugar en que este órgano se encuentra, sino en la boca del estómago, puesto que se maneja una concepción de la anatomía y de la fisiología distinta a la occidental. En esta concepción, las cosas o las plantas también tienen su alma o su corazón: ruk'u'x kem se traduce como "corazón del tejido, esencia, el nawal", y ruk'u’x che' se refiere a "corazón del árbol, la esencia, el centro del árbol".

Generalmente, hablar sobre sexualidad entre mujeres, entre hombres, o en espacios mixtos - mujeres y hombres- provoca risa y nervios, lo cual denota que se suscita placer al tratar el tema ${ }^{3}$. Lo que se ha podido observar es que algunas mujeres sienten placer al hablar sobre este tabú. En grupos de mucha confianza se aborda este tema en las pláticas, los chistes y bromas. Así, entre broma y broma van expresando sus sentimientos, sus emociones y sus experiencias. La broma se construye sobre aquello que se parece al falo o a la vulva. Algunas mujeres y jóvenes bromearon, expresando libertad y deleite, y dieron rienda suelta a su imaginación y al sentimiento de alegría.

Para referirse en tono jocoso al sexo se usan analogías:

\footnotetext{
${ }^{3}$ La expresión de la risa se puede observar en conversaciones informales entre personas y, especialmente, en el q’ejelonik (reunión colectiva y festiva).
} 


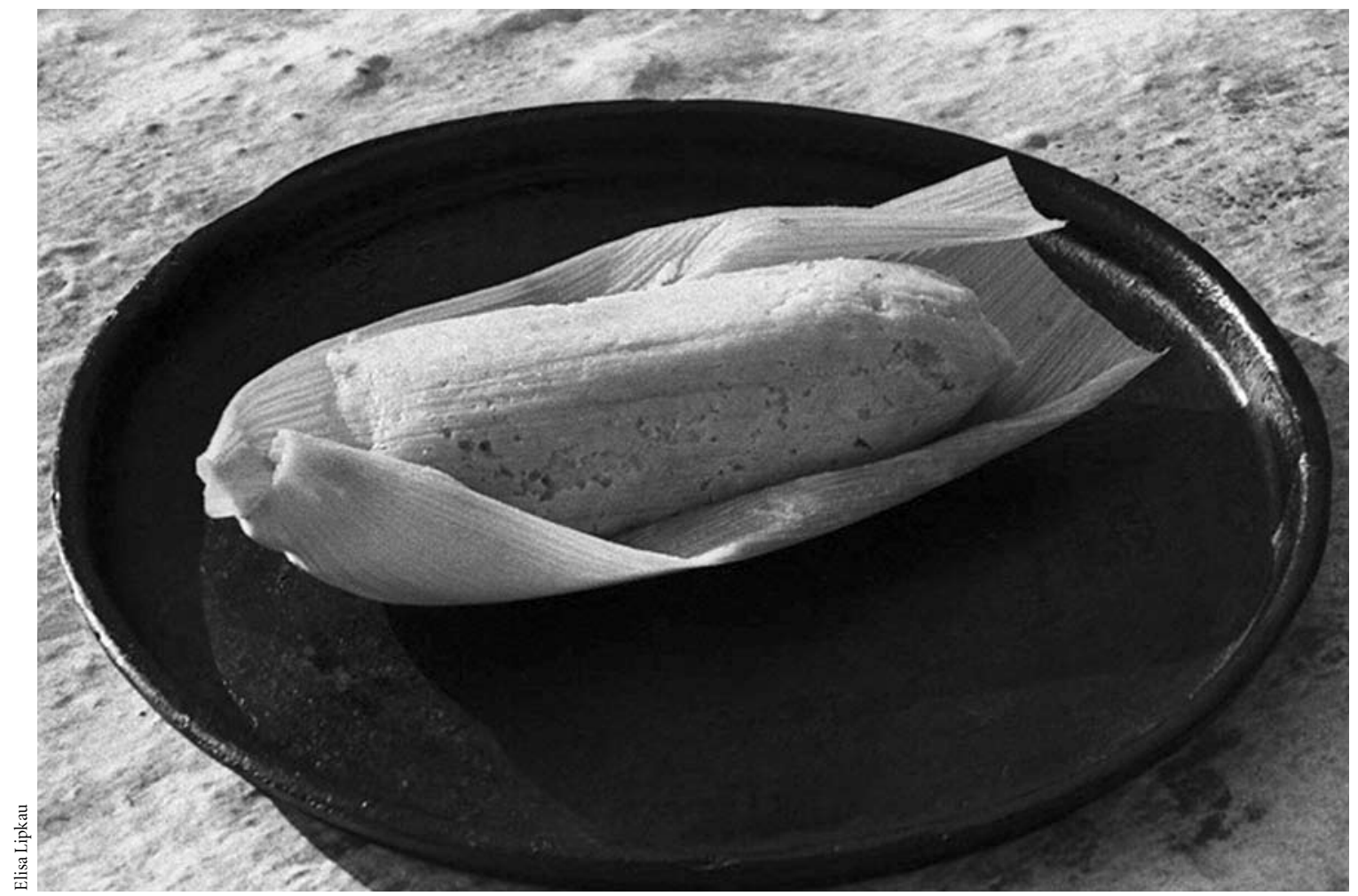

mes (gato), saq'ul (banano), ki' (rico), ik (chile). A lo largo del trabajo registré muchas frases de doble sentido o bromas con connotación sexual. Por ejemplo, cuando las mujeres cocinan el chile algunas dicen:"Ay kan chix wa' an, tzawi ri ik kan poralgo kan kiäq' jajaja” (Ay qué feo es, ¡ay, este chile es tan grande y rojo! jajaja), y la frase invita a reír a todas. Ante esta broma, las mujeres con pensamiento conservador reaccionan con cara larga y regaños. Dos de ellas se expresaron así: “ ¡Ay chix tan asquerosas, ya son grandes y miren lo que están enseñando!” Otra señora anciana agregó: “¡Venimos a trabajar, no a reírnos! ¡Aquí debe haber respeto!", pero una señora del grupo no conservador le respondió tranquilamente: "Sólo estamos haciendo chistes".

Las mujeres se ríen y, pasado un momento, alguna retoma el tema y le agrega una expresión jocosa más, vuelven a reírse y continúan la conversación con nuevas bromas, hasta que alguien cambia de tema. Las mujeres más atrevidas, con mayor experiencia y con sentido del humor, son quienes hacen comentarios jocosos y guían la conversación en el grupo, durante la cual ocurre un proceso de retroalimentación de la broma.

Existe una gran riqueza de significados al hablar en kaqchikel sobre el cuerpo vinculado a la sexualidad, lo cual prueba el interés que este tema despierta. Estas expresiones, que se comunican en contextos cotidianos, son muestras de las formas colectivas y culturales que el lenguaje adopta para referirse, en tono informal y festivo, a la sexualidad.

Para ahondar en lo dicho, presento otras frases de esta índole captadas en el trabajo de campo:

- Sobre el plátano. Una mujer invita: "Qa ch'olo' ri saq' ulk'a" (pelemos el banano, pues), y otra le contesta: "A saber si este banano aguanta", mostrando un banano aguado. Una tercera sugiere: "Sería bueno que le pasaras un poco de pom, así se componen”, y sueltan la risa. 
- Con el tamalito. Una mujer pide este favor: "Tiba'na' utzil nib'anta nim rak'än ri suba'n, kan rak'än tzik' in nib'anche' jaja" (haga el favor de hacer largo el tamalito como el tamaño del pene, ja, ja), y con el movimiento de la mano al hacer el tamalito dice: "Kan na sirisape" (cómo lo redondeás o cómo lo estás boleando); las demás se sueltan a reír y otra agrega: “Ay rat la' utz nana” lo que nib'an chawe" (jah!, vos te gusta lo que te hacen), y así continúan riendo.

Los ejemplos anteriores, extraídos del lenguaje coloquial, expresan los gustos, una relación con el cuerpo y el placer de la sexualidad.

Para referirse a la actividad sexual propiamente existen distintas expresiones, algunas son: nab'än achk na' (algo estás haciendo) y nak'än apo ruwäch jun achin (te estás metiendo con un hombre; esta frase la dice una madre a una hija, o una mujer a otra mujer). La frase $x a$ yiq'ojoman (estoy tocando música) fue dicha por un hombre.

Entre las expresiones que invitan a la actividad sexual están: yatin roqij pa ch'at (te tiro en la cama) y yatin chop hombre. Según las mujeres, cuando las invitan a tener relaciones les dicen jo' pa awän (vamos a la milpa) o jo' chuwaxan (vamos a la pared). Esta última frase es utilizada por los jóvenes. Una forma de expresarlo respetuosamente es tasipaj jub’a chuwä (regálame un poco). Las mujeres también hablan sobre los ofrecimientos atrevidos de algunos hombres; entre estas frases están ninb’än jub'a chawä (te van hacer un poco). Cuando se refieren a la actitud de las mujeres dicen $x$ b'an kan chre ixoq' (le hicieron a la mujer); cuando ella tiene deseos, nrajo' jub'a ri ixoq cha' (quiere algo la mujer) o tasipaj jub’a chwä (regálame un poco).

\section{CAMBIOS EN EL CUERPOY CÓMO CUIDARLO}

En el caso de las adolescentes, el cuerpo cambia, nacen diversos sentimientos e inicia la conexión con la sensualidad. Una de las entrevistadas refiere cómo dos situaciones fuertes en su vida —el terremoto y la violencia — apagaron su memoria y los sentimientos acerca de los cambios en su cuerpo. Victoria nos cuenta su situación:

Ay, yo no recuerdo por tantas tensiones que tuvimos, el terremoto, la violencia, yo sólo recuerdo cuando me vino la menstruación y me asusté mucho porque no tenía qué usar, no había ropa interior, casi no usaba. No me di cuenta cuando me crecieron los pechos, no sentía vergüenza porque casi nadie me decía nada, nunca nos prepararon para eso.

Marta, al contrario, fue consciente de sus cambios y esto le permitió hacer comparaciones: "Ah, de todos modos uno dice xinok wa läq ixöq re, xeki' iy pe nutz'um, así es esto, me crecieron mis pechos, ya no soy niña”. El crecimiento de una parte de su cuerpo marcó esa transición de niña a adulta.

En la adolescencia, son las madres quienes socializan la prohibición, el miedo y la negación. ¿Qué hay detrás de lo prohibido y el miedo? ¿Cuáles son las instituciones que crean y reproducen el miedo y lo prohibido? Cuando ya no se puede dar alguna argumentación se opta por el NO, y negar se traduce en rechazo, en exclusión, desestimación, barrera, lo cual produce más ausencias, separa lo que está unido, traza fronteras. En las relaciones de poder la negación es importante porque impide abrir las bases de la libertad tanto para conocer el tema de la sexualidad como para adquirir los conocimientos sobre su práctica.

A esta edad se refuerzan, por parte de la madre, las recomendaciones basadas en el peligro:

\footnotetext{
"Tienes que cuidar de tu cuerpo, que no te vaya a tocar ninguno, es peligroso si te va tocar una vez, peor si ahorita pasa su menstruación. Rápido se queda embarazada. Peor si ahorita se pasa de esa cosa [se queda embarazada]". Ella me dijo así, si a una mujer le toca, rápido se queda embarazada. Así como uno ahora con experiencia se queda, ya con tres o cuatro se queda con experiencia, se aprende.
}

La madre y algunas prácticas culturales han sido las responsables de la normalización de la conducta de las mujeres, pero a veces en los mensajes que transmiten pueden identificarse posturas contradictorias, por ejemplo, es común escuchar frases como éstas: "Ningún cerote se va aprovechar de mi hija", y por otro lado: "La mujer tiene que obedecer a su marido, no debe levantarle la voz, él es el que manda". Estas frases de doble adscripción ilustran las direcciones a seguir en su conducta por las mujeres 
indígenas: o se convierten en las eternas sirvientas de sus maridos o marcan el paso para revolucionar el dominio patriarcal.

Las madres, la cultura, la Iglesia, socializan pautas de conducta que conducen a la prohibición. Es común escuchar las siguientes frases: "no debés ver", "no debés tocarte alli”, "no debés beber", "no debés sentir cosquillas", "no debés estar sola con un hombre ni con familiares y menos aún con desconocidos", "no debés hacer caso al ladino porque él nunca se casará con vos", "tené cuidado con los bolos, se hacen los bolos para manosearte”.

El poder también aplica la ley de prohibición. La Iglesia y las leyes refuerzan la vigencia de las prohibiciones para mantener el status quo porque su establecimiento implica mantener las relaciones de dominación. En el marco de la moralidad, lo prohibido se convierte en sinónimo de temor, de peligro, y se le asocia al pecado, por lo tanto, el principio de cuidado, que impulsa la salud y la vida de la persona, se transforma en un mecanismo de control que congela la libertad y los sentimientos de placer y de amor.

Estela, la más joven de las mujeres entrevistadas, nos comparte su experiencia: cuando empezó a sentir los cambios en su cuerpo, le comenzó a dar importancia al cuidado del pelo, los pies y las uñas porque "le gusta que se miren bien". Ella es una de las entrevistadas que tiene una alta autoestima y lo demuestra en la valoración hacia su cuerpo:

Me gusta cuidarme toda y como a veces yo molesto con mis amigas y les digo: "yo soy bien bonita", entonces yo les digo: "yo tengo autoestima”. A mí me gusta cómo soy, porque la mayoría de mujeres dicen: "no me gusta esto, no me gusta lo otro", pero yo me siento bien, me quiero como soy. Acepto mi cuerpo tal y como es. Yo miraba que mi cuerpo estaba bonito [risas], pero cuando uno es niña es normal que el cuerpo esté recto y yo empecé a notar las curvas, las caderas se ensanchan, sólo eso recuerdo.

La capacidad para apreciar el cuerpo y aceptarlo es una motivación para ser positiva en la vida. Otro elemento que la ayudó a despejar su curiosidad es que no le ocultaron el tema de la sexualidad. La censura en este tema motiva, aún más en la niñez y la adolescencia, a recurrir a otros medios que no forman sino que desinforman. Generalmen- te, las mujeres que pertenecen a familias pobres y que realizan múltiples actividades para sobrevivir no se dan cuenta de los cambios que experimentan sus hijas, mientras que a otras sus madres les prohiben arreglarse para evitar la mirada de los hombres. Las historias y las experiencias son múltiples, y es necesario visibilizarlas para comprender la realidad de las mujeres indígenas.

\section{MUJERES CUIDADORAS DE LOS CUERPOS}

Las comadronas o especialistas del cuerpo femenino siguen siendo reconocidas. En muchas familias su palabra sigue siendo escuchada y, por lo mismo, es reconocida como la autoridad ancestral que da atención especializada para los cuerpos femeninos.

Todas las comadronas rezan antes de iniciar su trabajo en el tuj (temascal) ${ }^{4}$. Invocan a la dueña del tuj y también al fuego para que le den salud al cuerpo de la mujer y para evitar complicaciones, como podría ser un desmayo.

Para el baño de mujeres se sigue utilizando el "doblador o tusa", que tiene que ser grande para llamar el vapor, y el $t o l^{5}$, que sirve para cubrirse la cara y protegerse del calor. Las comadronas siguen usando también el jabón de coche o jabón negro, con el cual no sólo enjabonan el cuerpo, sino que, gracias al efecto del movimiento circular, estimulan la circulación de la sangre en los lugares del cuerpo que están fríos o tensos.

Victoria cuenta su experiencia:

\begin{abstract}
Yo lo he usado, me he bañado con varias comadronas, porque recuerdo que me dijeron que me habían bajado la matriz, y como al bajar eso cómo duele, y me recomendaron el temascal, pues, porque alivia un poco el dolor y probé pues, casi como seis o siete comadronas. Todas bañan diferente. Tuve la oportunidad de conocerlas a ellas, por pura necesidad.
\end{abstract}

Las comadronas detectan la caída de la matriz por los siguientes síntomas: dolor en el vientre, a veces se presenta

\footnotetext{
${ }^{4}$ Sobre el temascal o baño de vapor en Guatemala véase Virkki, 1962.

${ }^{5}$ Recipiente hecho de morro que tiene varios usos en la cocina y el temascal. Lo utilizan las mujeres.
} 


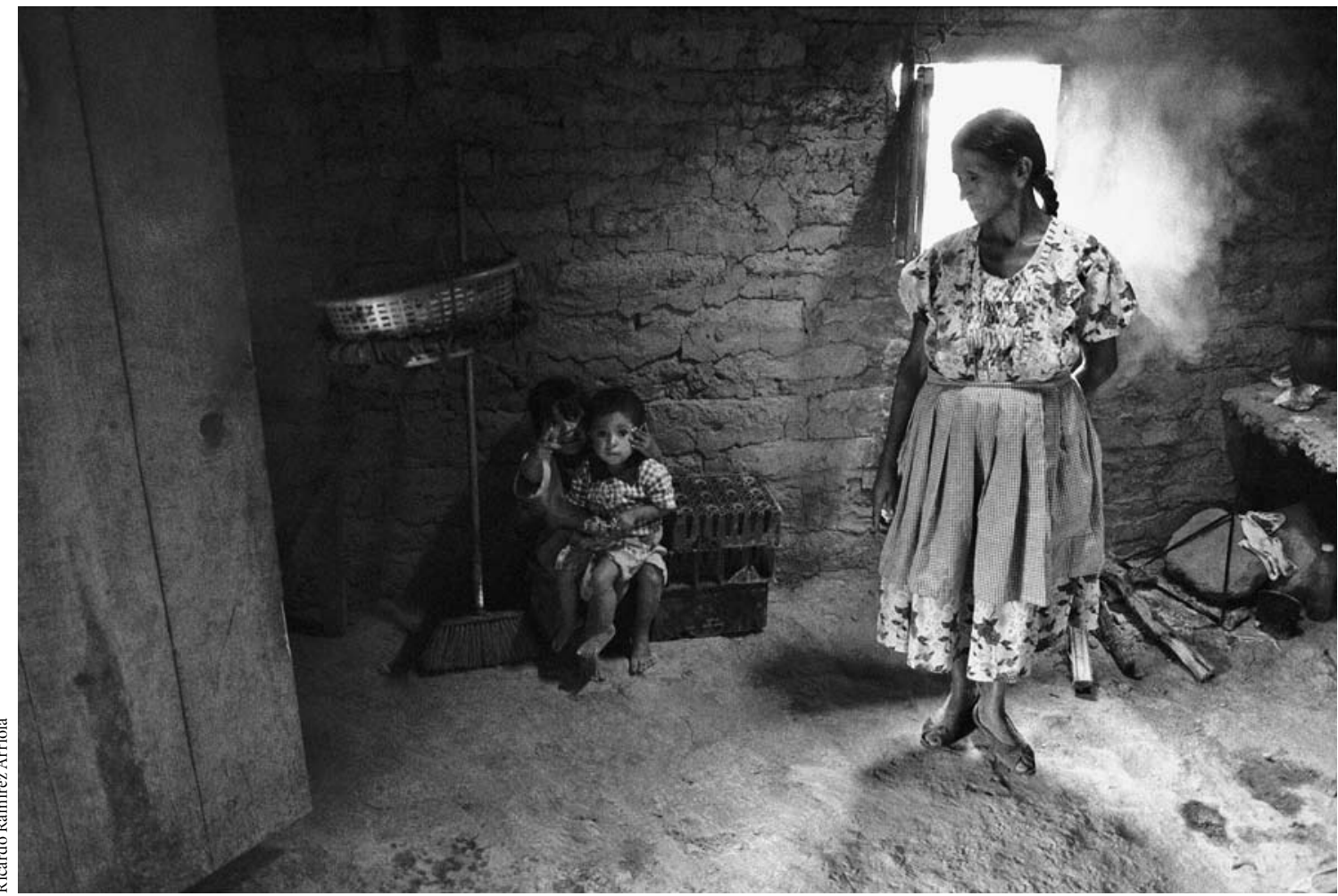

Jalapa, Guatemala, 2004.

dolor de espalda y al caminar casi se duerme el pie, además de presentar dificultades para caminar. La caída de la matriz se dice en kaqchikel xq'a apam, o xuya' vuelta a pam o rob'olqotin ri' ruk'u'x apam (se te cayó el bajo vientre, se te volteó la matriz).

En los temascales ${ }^{6}$ se acostumbra poner bancos largos donde uno puede sentarse o acostarse. La mujer que toma el baño recibirá su tratamiento acostada, posición adecuada para que la comadrona la sobe o le dé masajes. La mujer, al finalizar el baño, puede aprobar o desaprobar el trabajo de la comadrona, pero generalmente la expresión que emite es: "Esta señora sí sabe bañar".

El encuentro de los cuerpos femeninos, el cuidado del

\footnotetext{
${ }^{6}$ En los últimos años el temascal ha sufrido un proceso de extinción por factores espaciales, económicos y culturales. Las familias no cuentan con espacio para construir un temascal ni con recursos para invertir en su construcción, además de que el personal de salud con ideas "modernizantes" desacreditó el uso del temascal.
}

cuerpo de una mujer por otra es una de las expresiones del principio del cuidado: "Nos bañábamos juntos con ella, para mí no era tan extraño, de vernos como mujer, tal vez porque ya somos maduras", "no hay vergüenza, no, nada, y lo que hacía ella pues ella sabía bañarse bien, el primer temascal, me cayó bien, me calentó”.

En las entrevistas pude identificar los conocimientos y las técnicas que siguen aplicando las comadronas actualmente:

- Entrada: rezan a la abuela o nawal del tuj y al fuego.

- Cuando echan agua a las piedras se levanta el vapor; en ese momento la comadrona coloca un trapo mojado o un tol en la cara a la mujer que recibe el cuidado.

- Momento del masaje: la comadrona da masaje utilizando el jabón de coche. Inicia con los pechos, el estómago, el vientre y las piernas. Eleva las piernas de la mujer y golpea la planta de los pies con el puño o con el jabón. 
También le da golpes en las manos. Sopla en algunas partes del cuerpo con el objetivo de sacar el aire frío y que entre aire caliente.

- Salida: se recomienda acostarse, "es importante descansar, acostar y dormir un rato". En el proceso de relajamiento se comparten bebidas calientes o cerveza.

- Sensación: "Me siento como mujer nueva."

Las comadronas recomiendan tomar bebidas y té de plantas medicinales. Si la enfermedad es fría es aconsejable tomar algún té caliente. A las niñas y los niños que orinan en la noche, si no es un problema psicológico, si tienen frío en el estómago, se les recomienda utilizar el tuj. Se sabe que otro beneficio del tuj es que estimula la producción de leche materna. El masaje en el pecho tiene este objetivo. La más anciana de las entrevistadas refiere que tuvo abundante leche, se le regaba, a veces trataba de sacar para evitar que se le formaran bodoques (bolas duras alrededor de los pechos) y prevenir una mastitis o infección del pecho. Ella se pregunta:

¿Por qué las mujeres ya no tienen suficiente leche y por qué el uso de las pachas [biberones]? Antes las mujeres tenían mucha leche, pero ahora saber por qué ya no tienen, qué hicieron estas mujeres digo yo, están utilizando la pacha. Yo antes de ir al monte le daba leche a mi hijo y cuando regresaba, me dolían mis pechos, un día de trabajo en el monte, yo ayudaba al hombre al trabajo, me sobraba la leche.

Entre las mujeres que eran madres antes se solía regalar leche a algún niño que la necesitara. A veces se ausentaba la madre y otras mujeres se solidarizaban y le daban pecho a la niña o el niño que lloraba por hambre. En las últimas tres décadas, las mujeres indígenas que han optado por un trabajo asalariado se ven obligadas a alimentar a sus bebés con pacha.

También son relevantes los elementos que corresponden a la parte subjetiva de los beneficios del tuj y la relación que mantiene con los cuerpos. La reunión entre una comadrona y una mujer que recibe un cuidado especial es el encuentro entre una sanadora y una mujer que es sujeto de sanación, el encuentro de dos cuerpos femeninos. Los cuerpos desnudos expresan una forma de comunicación. Las mujeres valoran la experiencia de la mujer sanadora, y esconden o entierran la vergüenza, dejándose cobijar por la confianza y la seguridad que inspira la comadrona. Las mujeres que reciben el cuidado de éstas experimentan una sensación de bienestar y de libertad. Las comadronas tienen la capacidad de identificar la geografía del dolor o del bienestar en el cuerpo. Limpian las energías negativas y refuerzan las energías positivas. Por eso al temascal se le considera como el lugar que contribuye a la limpieza espiritual, mental y física de las personas.

Las niñas y los niños que han tenido la oportunidad de experimentar el temascal construyen el sentido del cuerpo y la desnudez sin morbosidad. Adquirir un concepto del cuerpo muy humano a partir del descubrimiento de sí mismo y de la percepción de otros cuerpos constituye una base para la construcción del respeto hacia los cuerpos femeninos o masculinos. El tuj es un espacio donde se puede observarla diferencia humana, en cuantoa cuerpos masculinos y femeninos, y también la diferencia generacional, cuerpos infantiles, adolescentes, jóvenes y ancianos. Captar esta diversidad es comprender que los cuerpos son diferentes en tamaño, color, y también en olor. Este conjunto de elementos constituye la materia básica para la construcción de conceptos y relaciones más humanas y ricas en las sociedades, no sólo en la cultura maya sino en otras culturas que sacralizan el dolor y han sepultado el placer.

Si la percepción de los niños sobre el cuerpo femenino es estimulada en el tuj a temprana edad, éstos podrán desechar los estereotipos y otras ideas falsas que inducen a la objetivación del cuerpo de la mujer. En el $t u j$, sin mayor discurso, los cuerpos comunican, lo cual permite aclarar dudas y prejuicios, e invita a reflexionar sobre la urgente necesidad de saber quiénes somos, sin ropajes que nos escondan, para fortalecer nuestras identidades. La construcción social del cuerpo suele reflejar la diferencia y cuando éste es percibido desde el modelo dominante, las desigualdades e injusticias sociales quedan plasmadas en el discurso y en las actitudes, por ejemplo, cuando se valora a los cuerpos grandes en detrimento de los cuerpos pequeños, o los cuerpos blancos frente a los cuerpos de color. Bajo este paraguas se ha construido la superioridad de algunas culturas.

La salud del cuerpo de las mujeres mayas comalapenses depende de algunas prácticas sociales humanizantes 
que promueven la vida y el bienestar de las personas pero, ante todo, del cuidado prodigado por las manos, el conocimiento y la sabiduría de las comadronas. Ellas han sido quienes han fortalecido el principio de cuidado entre las mujeres. El trabajo de las cuidadoras del cuerpo es más una expresión de resistencia que un mantenimiento de la "tradición", tal como ha sido percibido por los antropólogos modernistas. Esta resistencia reside en la reproducción y vivencia de prácticas ancestrales que promueven la vida.

En relación con el uso del temascal, varias informantes guardan recuerdos positivos acerca de éste. Victoria relata su experiencia al respecto cuando era niña:

Recuerdo cuando nos bañábamos, así de pequeñas. Yo llegaba a espiar allí en el temascal, como sólo ponía un poncho así ve, qué bueno que taparan así todo, sino medio colgado. Llegaba a espiar a los que se estaban bañando. Mi mamá o mi abuelita así eran sus pechos (así de grandes), se colgaban sus pechos y bañándolos a todos ahí, y cuando salían, uno por uno los sacaban.

Generalmente son las mujeres, sobre todo las madres, quienes se encargan de bañar a los pequeños. La temascaleada es otra actividad femenina; las responsables de bañar a las niñas y los niños son las madres. A esa edad las entrevistadas, siendo niñas, vieron como algo normal el baño colectivo femenino. Desde niña Marta ha utilizado siempre el tuj, siempre ha confiado en sus beneficios. Actualmente se temascalea con sus hijos.

Cuando las mujeres tienen vida de pareja, por lo general entran los dos al tuj. En la primera temascaleada hay un poco de vergüenza, pero poco a poco ésta desaparece: "Lo mira el cuerpo de uno y es diferente al otro cuerpo, al principio cuando uno se mete con un hombre no es igual, se siente mal, pero ya después no". En el tuj aprenden a practicar la reciprocidad, la mujer enjabona y raspa la espalda del hombre y él hace lo mismo con ella: "Porque uno no puede raspar la espalda uno con su propia mano, no se puede". Esta práctica en kaqchikel se dice ninjos a wij (te rasco la espalda).

El tuj es considerado como un espacio para apreciar los cuerpos, los olores y la desnudez. Respecto a la apreciación de la desnudez los hombres dicen que no sintieron vergüenza: "Casi no siente nada, mirás tu cuerpo, mirás el otro, casi no sentís nada". Lo mismo refiere la más anciana del grupo de entrevistadas. Jesusa se casó a los 20 años aproximadamente, en 1942, y nos cuenta: "Sí lo bañé pues, ¿qué tiene eso? Como vivimos juntos, le lavo la espalda, lo baño con paxte, le hecho jabón, y él me hacía lo mismo, no teníamos vergüenza. Si entra alguien entonces sí se siente uno mal, como sólo los dos, entonces no”.

El $t u j$ ha sido un lugar donde las personas se bañan, donde aprecian los cuerpos, donde la pareja puede tener relaciones íntimas, donde se puede preguntar sobre el cuerpo y donde las mujeres son atendidas por las comadronas después del parto.

Un punto que deseo ampliar aquí es sobre los beneficios del $t u j$. Las diversas generaciones han transmitido, a través de la narración oral, conocimientos y prácticas culturales acerca del $t u j$. Entre las familias kaqchikeles se aconseja el temascal no sólo para la higiene personal, sino como remedio para las enfermedades que tienen un origen frío o cuando a alguien "le ha pegado el aire". Sirve para calmar contracturas musculares y dolores de cuerpo causados por el estrés emocional o por el frío; corrige problemas en la circulación; previene y corrige várices y presión baja; acelera el proceso de cicatrización de una herida; alivia los problemas respiratorios; es útil durante el embarazo y el posparto. Es un espacio que cura, limpia y purifica el cuerpo y el espíritu, y es propicio para tener relaciones sexuales.

Acercarse a la corporalidad a través del lenguaje implica estar atento a las historias de vida, las percepciones, las vivencias, las relaciones de poder, los signos, los símbolos, las metáforas, las bromas, la desnudez, las transformaciones del cuerpo, la violencia, los placeres; y permite acercarse a los lugares donde otras formas de percibir son posibles y donde el cuerpo es aceptado sin sobresaltos.

La corporalidad expresada en el lenguaje propio, conectada con la naturaleza, con la lógica de la temperatura —frío-caliente- e interrelacionada con la intimidad y el respeto son factores y valores que se expresan cotidianamente, a pesar del sexismo, la violencia y la cosificación de los cuerpos y de los pueblos presentes en las familias.

Entre los kaqchikeles se guardan y se practican ideas, valores y creencias ancestrales que estimulan la asistencia de los cuerpos, y son las mujeres quienes sostienen el man- 
tenimiento de estas ideas y prácticas sociales. Desde la niñez y bajo el principio de cuidado se aprende a velar por el cuerpo y los cuerpos. El tuj o temascal es percibido como un espacio físico y social que contribuye a satisfacer las necesidades corporales. Las mujeres legitiman su utilidad porque éste sigue otorgando vida y bienestar a las personas y los pueblos. Las mujeres, el tuj, el lenguaje, las comadronas y el análisis crítico son elementos que dinamizan la cosmovisión indígena y que constantemente retan el pensamiento modernista del cuerpo.

\section{¿PIEZAS ARQUEOLÓGICAS O HISTORIA DE LOS CUERPOS?}

Una forma de acercarse al conocimiento ancestral del cuerpo es a través de las "piezas arqueológicas", como las denominan la arqueología y la antropología occidental. Estas disciplinas dan cuenta de la concepción que se tenía del cuerpo en la época prehispánica. Las piezas encontradas y salvadas de la destrucción general de que fueron víctimas los libros y documentos indígenas son una muestra objetiva de cómo las culturas prehispánicas miraron la figura humana, pero también son representaciones corporales que nos retrotraen al pasado para comprender el presente. Las antiguas culturas maya, nahua, tolteca, teotihuacana, huasteca nos han legado expresiones artísticas en las que es posible apreciar la figura humana. Lo mismo sucede en el antiguo Perú con las culturas salinar, vicús, virú y mochica ${ }^{7}$. Muchas de estas expresiones no sólo muestran la figura humana, sino signos e imágenes eróticas, sin un sentido negativo ni pecaminoso. Las imágenes y figuras humanas ofrecen distintas lecturas del universo y del cuerpo. Cada una de las partes corporales expresa relaciones y tensiones con el cosmos. A nivel subjetivo, estas

\footnotetext{
${ }^{7}$ Para ilustrar el sentido del cuerpo de las culturas prehispánicas me basé en Elogio del cuerpo mesoamericano, revista-libro número 69 de $A r-$ tes de México (2004), y en El arte erótico en el antiguo Perú (Larco Herrera, 1998), editado por el Museo Arqueológico de ese país. Muchas de las piezas arqueológicas expuestas en el número mencionado de Artes de México se encuentran actualmente en el Museo Regional de Guadalajara, el Museo Nacional de Nayarit y el Museo Nacional de Antropología de México. El Museo de Antropología de Guatemala guarda también varias piezas de la figura humana de los mayas.
}

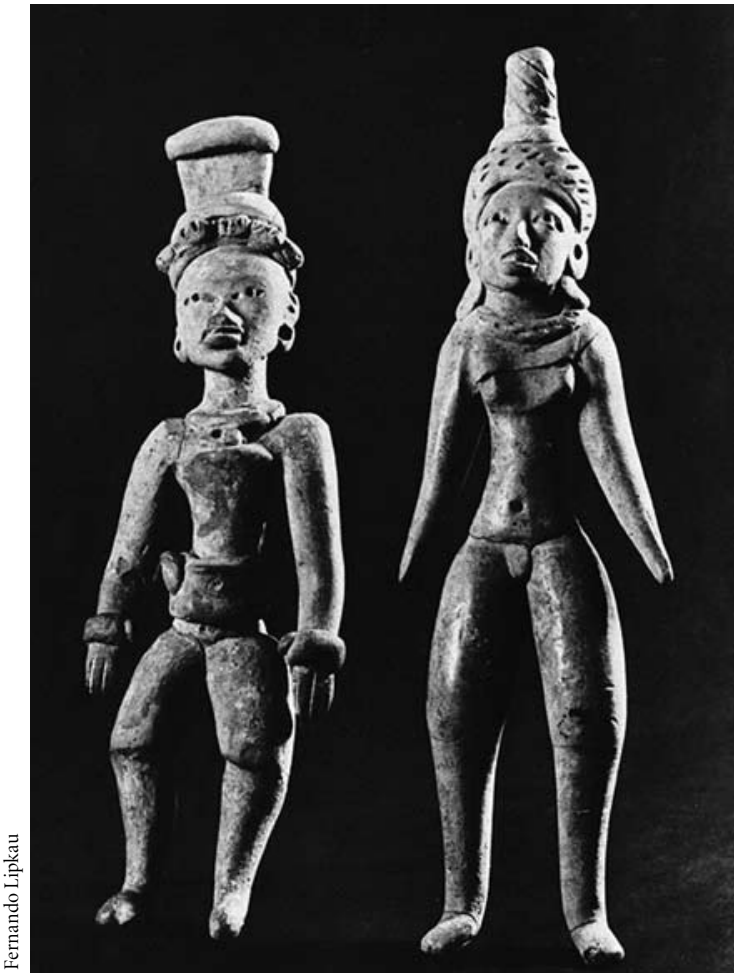

Figurillas femeninas de barro. Cultura huasteca. Museo Nacional

figuras humanas invitan a movilizar la conciencia étnica y genérica porque permiten analizar no sólo la historia y la cultura, sino también la identidad individual y colectiva. En mi caso personal, estas figuran reflejan mi estado de pertenencia, y forman parte de mi cultura, pues esos hombres y mujeres representados fueron mi gente. Son mis semejantes, mis antepasados, pues desciendo de ellos, soy una mujer maya. Estas figuras nos llevan a reflexionar y articular el pasado, o nuestro pasado, con el presente, o nuestro presente.

Otra manera de enriquecer el conocimiento sobre el cuerpo es a través de la historia. Es importante anotar cómo algunas historiadoras están aportando en la comprensión acerca del sentido del cuerpo. Elvira Sánchez-Blake ${ }^{8}$ analiza la imagen del cuerpo y lo que representa históricamente:

\footnotetext{
${ }^{8}$ Comunicadora social colombiana.
} 


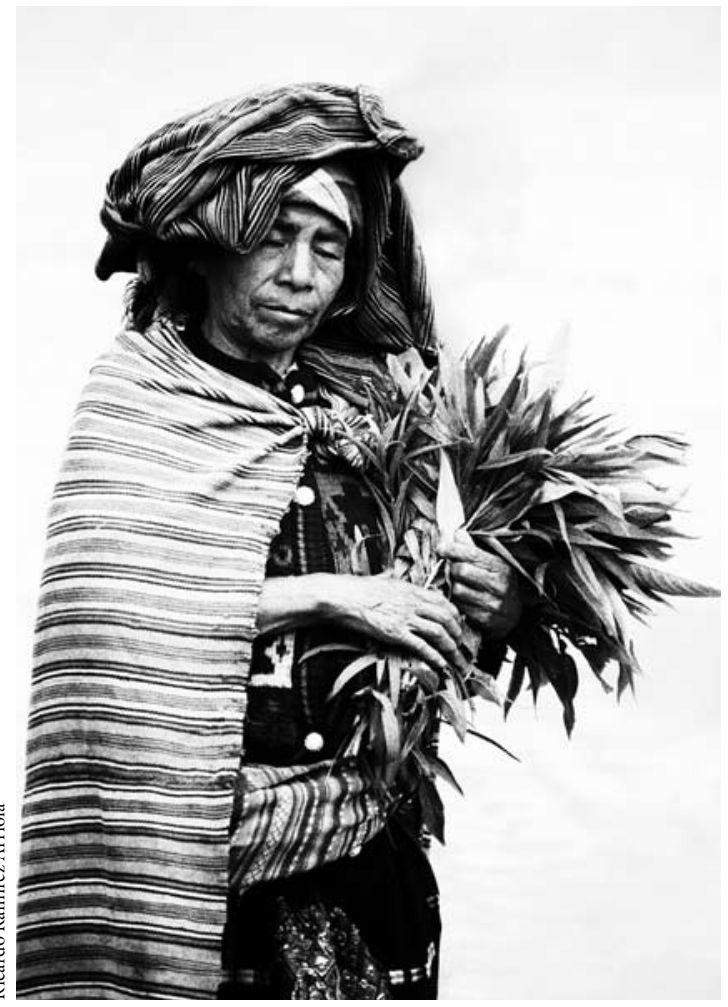

Totonicapán, Guatemala, 1999.

La escena inaugural de Américo Vespucio ante una mujer desnuda que se incorpora de su hamaca es el punto del que parte Michel de Certeau para desarrollar su teoría de la escritura de la historia. Esta imagen prefigura el discurso de la colonización, la representación del Nuevo Mundo, América, como el cuerpo de mujer desnudo - la página en blanco- donde se escribe la historia, y la conformación del estado nación a partir de ese texto-cuerpo. Se establece así la relación entre cuerpo-texto-nación, base del estudio literario e historiográfico. En el caso concreto de Latinoamérica, por su circunstancia histórica y geográfica, y el efecto de la colonización, estos factores jugarán un papel decisivo en su desarrollo político y social (SánchezBlake, 2001: 7).

Analizar el cuerpo desde el punto de vista histórico y político permite traer a la memoria la invasión del nuevo mundo. Este hecho impuso un modelo sexual y un modelo de belleza. Al respecto, Miguel Güémez Pineda señala: "Se han impuesto modelos de belleza occidental y sus pro- totipos masculino y femenino están regidos por los rasgos físicos europeos como la piel blanca, el cabello rubio y los ojos claros" (Güémez Pineda, 2000: 314). Esta influencia occidental, que Güémez Pineda define como "la colonización del cuerpo", implicó para las mujeres indígenas silencio, atropello, su uso como mano de obra barata, y vivir atadas a la servidumbre y al esclavismo, a la monogamia y a la construcción de la ideología del mestizaje, ideología que "se hizo con base en la explotación y violación de las mujeres indígenas y negras. Las mujeres fueron siempre instrumentalizadas para satisfacer el apetito sexual del hombre blanco y así asegurar la mezcla de sangres para mejorar la raza. Política de blanqueamiento alimentada y promovida por los Estados incipientes" (Curiel, 2007: 98) para legitimar la explotación, la servidumbre y el trabajo doméstico.

Sobre la concepción del cuerpo es importante recordar cómo los españoles se escandalizaban por la desnudez de los indígenas, cómo Colón se sintió "escandalizado por la desnudez del otro" (Todorov, 1989: 47). Se establecieron instituciones responsables del adoctrinamiento sobre el cuerpo, que tenían como fin convertir a las personas en un ser social moralizante y que motivaban a racionalizar el dolor, la culpa, el castigo, la explotación, la doble moral y el temor al dolor.

El primer cuestionador de la desnudez de los indios fue el pequeño grupo de españoles que invadió el territorio, pero los más moralistas fueron los curas españoles, que cuestionaron el hecho de que los indios llevaran tan escasa ropa. Colon narra su encuentro con los habitantes de estas tierras: "Esta gente es muy mansa y muy temerosa, desnuda como dicho tengo, sin armas y sin ley", "los indios se asemejan porque todos están desnudos, privados de características distintivas"'"particularmentelos pertenecientes a estratos sociales más bajos" (Todorov, 1989: 44) (pues debe recordarse que el atavío era otro signo de la posición social). El cronista dominico Tomás de la Torre asentaba que en el pueblo tzotzil de Zinacantán, Chiapas, los hombres andaban desnudos, y cuando el frío o la fiesta los forzaban a vestirse, se ponían tan sólo una manta anudada sobre los hombros. Por su parte, su correligionario Ximénez señalaba que en Guatemala, los vestidos "eran tan pocos que casi no pueden llamar tales" (Ruz, 1996). 
Ejemplos más recientes de reprobación ante la desnudez e imposición ideológica son el de las mujeres de Cahabón (Guatemala), quienes antes no se cubrían los pechos y ahora la única que se viste así es una abuela; y el de las mujeres poqoman de Palín, quienes solían usar un huipil corto que les cubría únicamente los pechos hasta que el general Ubico ordenó que usaran huipiles largos ${ }^{9}$. Frente al dilema que desata la desnudez, en el que por un lado persiste el deseo y la libertad de mostrar el cuerpo, al final, en esta sociedad tan opresora resulta más fácil apagar la libertad con la cosificación del cuerpo de las mujeres, tanto indígenas como mestizas. Para los hombres indígenas la desnudez genera una ambivalencia que fluctúa entre el deseo de ver y a la vez ocultar el cuerpo. En los hombres ladinos provoca una ambivalencia racial que, unida a la ansiedad, es expresada en chistes en los que subyace un fondo burlesco que deja entrever una autotraición que pone en causa su parte india. Según Diana Nelson, los chistes:

[...] ayudan a entender la diversidad de formas complejas en las que se apoyan en el género los cuerpos políticos étnicos y nacionales. El traje tradicional de las mujeres mayas ocupa un lugar destacado en los chistes y parece marcar un espacio de particular ambivalencia o desafío a las nociones de identidad étnico nacional [...] por eso el corte (la larga falda envolvente de las mujeres mayas) es tema de interés particular en los chistes, en muchos de ellos con la idea de "desenvolverlo" (Nelson, 2006: 298) ${ }^{10}$.

En la ambivalencia racial, continúa Nelson, "permiten que los ladinos satisfagan sus instintos contrarios” (Nelson, idem). Existe el simbolismo de desnudar a las mujeres indígenas con el fin de enviar el siguiente mensaje: "miren, ella no lo 'tiene”. Esto también refleja el "miedo ladino", el miedo a ver lo que no quieres ver. En la ambivalencia ra-

\footnotetext{
${ }^{9}$ Esta historia la cuentan actualmente las mujeres poqoman de Palín. Una mujer joven relata cómo ocurrió este cambio. Las mujeres poqoman solían vender fruta a las camionetas que iban a la costa sur, y al ofrecer sus frutas en canastos sobre la cabeza, se les levantaba el huipil, dejando descubiertos los pechos. En una de sus giras, el general Ubico observó esta expresión de desnudez, no le pareció bien y ordenó que las mujeres se cubrieran los pechos.

${ }^{10}$ Diana M. Nelson hace un análisis profundo del tema del género en la cuestión étnico-nacional en su libro Man Ch'itil. Un dedo en la llaga: cuerpos políticos y políticas del cuerpo en Guatemala del Quinto Centenario (2006).
}

cial se conjugan dos ideas, por un lado, el simbolismo de desnudar a las mujeres indígenas para afirmar que tienen un cuerpo deseable, pero qué lástima que ese cuerpo sea el de una india.

El pensamiento opresor, conservador y moralista ha obligado a las mujeres indígenas cristianas a cubrirse y vestirse "como la Virgen María", pero otras mujeres, sobre todo las más jóvenes, han transgredido esas formas de vestir conservadoras con el objetivo de mostrar un cuerpo asumido con libertad. Algunas mujeres han impuesto la moda de usar huipiles con cuello más escotado, o subir el corte para mostrar los "camotes" o pantorrillas. Las mujeres del pueblo q'eqchi', que viven en un clima cálido, se quitan el huipil y dejan expuestos sus cuellos y hombros. Otra manera de exponer con libertad el cuerpo es al amamantar mostrando el pecho, pues las mujeres mayas no se cubren ni ocultan a sus criaturas con "mantillas"11.

Las y los indígenas aprendieron a verse con ojos moralistas y a someterse. La implantación de esta mirada cambió el concepto del desnudo y de la sexualidad. Se aplicó otra visión, otro sistema de valor, otra forma de vestir ${ }^{12}$. Se los instruyó a vivir la sexualidad como pecado, como sucia e impura, como algo privado y como una actividad vergonzosa: "Así, sobre el deleite sexual se vaciaron los conceptos de transgresión e inmoralidad" (Ruz, 1996: 6). Se consideró que el cuerpo humano es indigno de disfrutar del placer.

Otro elemento de análisis en la percepción de los colonizadores hacia los indígenas es el siguiente: ellos vieron al indio como cosas, "porque después de todo, ellos también forman parte del paisaje" (Ruz, 1996: 26). Este pensamiento sigue vivo y lo reproducen los criollos, algunos mestizos y algunas instituciones del Estado. El Instituto Guatemalteco de Turismo (Inguat) y el Museo Ixchel, específicamente, continúan viendo los trajes de las mujeres mayas y los cuerpos con traje indígena como parte del

\footnotetext{
${ }^{11}$ Recomiendo leer la Historia del pecho de Marilyn Yalom (1997).

12 Esta afirmación no se realiza con el afán de legitimar la versión de la dominación ladina que señala que los trajes indígenas actuales los impusieron los españoles porque este argumento, y parafraseando a Diana Nelson, es para despojar al indígena de su traje y que el cuerpo muestre la igualdad nacional. Es posible que los encomenderos uniformaran a sus indios, pero no crearon los diseños mayas.
} 
paisaje $^{13}$. Por eso es importante revelar la historia de la sexualidad, porque revelarla implica desnudar la historia y confrontar una realidad de sometimiento hacia los pueblos indígenas por parte del Estado, la iniciativa privada y las ONG que trabajan con perspectiva folclórica y tutelar.

No obstante, pese a la invasión, la evangelización, la vida colonial, la modernidad y el capitalismo, la cosmovisión indígena y la resistencia de las mujeres indígenas cobran vida en la construcción de la autonomía y la autodeterminación de los pueblos y de los cuerpos. El cuerpo humano que hoy se menciona en los idiomas mayas está interrelacionado con la naturaleza y el cosmos, pero no ha sido asociado al territorio, porque el hacerlo implica ver al cuerpo como cuerpo político y al territorio como cuerpo de mujer, pues en las guerras y en el proceso de colonización, la última muestra de invasión ha sido la penetración o la violación sexual de las mujeres, en este caso de las mujeres indígenas. Es preciso recordar cómo "en la cultura patriarcal, las mujeres son vistas como propiedad de los hombres, y, en el contexto de la guerra, como propiedad del enemigo, la cual, como todas las otras propiedades, es expropiada y destruida a fin de debilitar a ese enemigo" (Consorcio Actoras de Cambio, 2006: XIV).

Hasta el momento, el movimiento indígena y las organizaciones de mujeres indígenas no han profundizado en este tema a partir de la invasión en los procesos de asimilación y en la guerra reciente en Guatemala ${ }^{14}$, y no hay que olvidar la violencia sexual a la que siguen siendo sometidas cotidianamente las mujeres indígenas por parte de hombres indígenas, mestizos y blancos.

Rescatar el sentido del cuerpo a través de las figuras humanas desde una mirada crítica permite rescatar la memoria, no para quedarnos en el pasado sino como una forma de engarzar ese pasado con el presente para así comprender la diversidad de las culturas, pero también la diversidad de conocimientos y verdades acerca de los cuer-

\footnotetext{
${ }^{13}$ En la junta directiva del Museo Ixchel no participa ninguna tejedora indígena, todas sus integrantes son mujeres "blancas" que viven del arte maya.

${ }^{14}$ Existe un aporte significativo que ha sido escrito por mujeres mestizas guatemaltecas en el libro Rompiendo el silencio. Justicia para las mujeres víctimas de violencia sexual durante el conflicto armado en Guatemala (Consorcio Actoras de Cambio, 2006).
}

pos. Los grupos sociales, especialmente los indígenas, por medio de su cosmovisión, han definido la corporalidad, y ésta ha sido el lugar privilegiado para expresar la comunicación con el mundo ${ }^{15}$.

\section{Bibliografía}

Consorcio Actoras de Cambio, 2006, Rompiendo el silencio. Justicia para las mujeres víctimas de violencia sexual durante el conflicto armando en Guatemala, La Lucha de las Mujeres por la Justicia, Instituto de Estudios Comparados en Ciencias Penales de Guatemala, Guatemala.

Curiel, Ochy, 2007, "Crítica poscolonial desde las prácticas políticas del feminismo antirracista", Nómadas, núm. 26, abril, Universidad Central, Bogotá, pp. 92-101, en línea: <www. ucentral.edu.co/NOMADAS/nunme-ante/26-30/nomadas 26/7-CR\%CDTICA\%20OCHY.pdf>.

Chirix García, Emma Delfina, 2003, Alas y raíces. Afectividad de las mujeres mayas. Rik' in ruxik' y ruxe' il ronojel kajowab' al ri mayab' taq ixoqi', Nawal Wuj, Guatemala.

García, Raúl, 2000, Micropolíticas del cuerpo: de la conquista de América a la última dictadura militar, Biblos, Buenos Aires.

Güémez Pineda, Miguel, 2000,"La concepción del cuerpo humano, la maternidad y el dolor entre mujeres mayas yucatecas", Mesoamérica, núm. 39, CIRMA, Guatemala, pp. 305-332.

Artes de México, 2004, Elogio del cuerpo mesoamericano, núm. 69, Artes de México, México.

Larco Herrera, Rafael, 1998, El arte erótico en el antiguo Perú, Australis, Lima.

Nelson, Diana M., 2006, Man Ch' itill. Un dedo en la llaga: cuerpos políticos y politicas del cuerpo en Guatemala del Quinto Centenario, Cholsamaj, Guatemala.

Ruz, Mario Humberto, 1996, "El cuerpo. Miradas etnológicas", en Ivonne Szanz y Susana Lerner (eds.), Para comprender la subjetividad. Investigación cualitativa en salud reproductiva y sexualidad, El Colegio de México, México, pp. 89-136.

Sánchez-Blake, Elvira, 2001, "Cuerpo-patria en la escritura de América”, En otras palabras... Mujeres, cuerpos y prácticas de sí, Grupo Mujer y Sociedad, Programa de Estudios de Género, Universidad Nacional de Colombia, Bogotá, pp. 7-16.

Todorov, Tzvetan, 1989, La conquista de América. El problema del otro, Siglo XXI, México.

Virkki, Niilo, 1962, "Comentarios sobre el baño de vapor entre los indígenas de Guatemala”, Guatemala Indígena, vol. II, Instituto Indigenista Nacional, Guatemala

Yalom, Marilyn, 1997, Historia del pecho, Tusquets, Barcelona.

\footnotetext{
${ }^{15}$ Sobre este tema véase también García, 2000
} 